\title{
Location of Logistics Center Planning of Changzhutan Based on Center-of-Gravity Method
}

\author{
Chen Wen-jun \\ Economic school, Central South University of Forestry and Technology, Hunan China ,410002
}

\begin{abstract}
This paper focuses its attention on the problem of facility location and provides an optimized static single-facility location model based on Center of Gravity. As an empirical analysis course, the final result where to establish a new logistics centre in Changzhutan in Hunan province. is an important reference for the government and enterprises.
\end{abstract}

Key words -Logistics center, Center of gravity, Hunan province

\section{Introduction}

Location planning is concerned with where to establish a new facility or relocate an existing facility to achieve a certain objective. The facility could be a retail store, a distributing center or a logistics center while the objective was to minimize distance, minimize cost, or maximize equity. The study of facility location and related issues dates back to the early 17th century, but location theory was not formally introduced until the beginning of the 20th century (Love, Morris, \&Weslowsky, 1988). Today, location planning, which is a comprehensive and systematic project in supply-chainmanagement, has become a popular research area, with applications in a wide array of industries including manufacturing, transportation, healthcare , education, and airline, among others.

In China, the logistics is developing rapidly. Compared with the "1 +8 " Wuhan Province city circle, the regional cooperation in Hunan Province, which is one big province in the central of China, have expanded from three nearby cities ChangSha-Zhuzhou-Xiangtan(CZT) agglomeration to the " $3+5$ " city agglomeration, including other big five cities. Now, the " $3+5$ " city agglomeration initially formed city group architecture, operation mechanism and operation mode. The government, enterprises, and third-party logistics are very concerned about the logistics distribution centre location problem.

The significance of location analysis in the business world is evidenced by the many college text books on operations management. It is the actual application of the center of gravity (COG) method and the rapid development in logistics in Hunan Province in China that motivates this paper

\section{About Center of Gravity}

The COG method is a mathematical technique used for finding the location of a proposed distribution center that will minimize the total distribution costs. The method is suit for the mini-sum single facility location problem. It takes into account the location of markets, the volume of goods shipped to those markets, and shipping costs in finding the best location for a distribution center.

\subsection{Distance in COG}

Three different distance measures are widely used by location planners. First, rectilinear distances are appropriate in metropolitan areas since travel takes place along orthogonal streets. They are also pertinent in many production plants, where materials are moved across aisles in crisscross patterns. Second, there exist countless situations in which Root distances are useful. For instance, air flight tends to follow a straight-line path, so does movement of parts on a conveyor. Finally, as an example application of squared Root distances, it has been reported that fire loss generally increases with the square of the root distance between the disaster site and the fire station. If there are two facilities $\times 1(a 1, b 1)$ and $\times 2(a 2, b 2)$, the three kinds distance are list as following:

$$
\begin{gathered}
\text { Rectilinear distance }=|\mathrm{a} 1-\mathrm{a} 2|+|\mathrm{b} 1-\mathrm{b} 2| \\
\text { Root distance }=[(\mathrm{a} 1-\mathrm{a} 2) 2+(\mathrm{b} 1-\mathrm{b} 2) 2] 1 / 2 \\
\text { Squared Root distance }=(\mathrm{a} 1-\mathrm{a} 2) 2+(\mathrm{b} 1-\mathrm{b} 2) 2
\end{gathered}
$$

Different kinds of distance have different use, so we must carefully consider what kind of approach to calculating. In addition, the transportation rates are closely related with the distance. The transportation rates were either linear with distance as approximately with truck rates or tapered as approximately with rail rates, as the squared root of distance. Because truck is the dominant transportation mode in CZT, the three major cities groups, is closely linked within one hour, the freight rates can be considered linear. So, the root distance is used here and the error can be as little as 1/10th of that with rail[4].

\subsection{Assumptions in COG}

The COG method assumes that transportation cost is directly proportional to or linearly with distance between facilities on the map as well as the volume shipped. And this method assumes that inbound and outbound transportation costs are equal, and it does not include special shipping costs for less than full loads.

\subsection{Algorithm of COG}

The location selecting by COG method begins by placing the existing locations on a coordinate grid system. The choice of coordinate systems is entirely arbitrary, just as long as the relative distances between locations are correctly represented. 
This can be done easily by using longitude and latitude coordinates grid over an ordinary map.

The supporting or distribution facility is then found by calculating the $\mathrm{X}$ and $\mathrm{Y}$ coordinates that result in minimizing the distribution costs among all facilities. To determine this location on the grid map, the basic inputs to the model and formulas are as follows:

$\mathrm{X} n, \mathrm{Y}$ n: Coordinate location of either a market or source $\mathrm{n}$.

$\mathrm{Cn}$ : Cost of shipping one unit for one mile between the facility and either market or supply source $n$.

Vn: Volume of good transported to the nth. market or supply source.

If $(x, y)$ is the location selected for the facility, the root distance dn between the facility at location(x,y) and the supply source or market $\mathrm{n}$ is as follows:

$$
d_{n}=\sqrt{\left(x-x_{n}\right)^{2}+\left(y-y_{n}\right)^{2}}
$$

Then the total transportation cost $\mathrm{F}$ is as follows:

$$
\mathrm{F}=\sum_{i=1}^{n} d_{i} w_{i} c_{i}
$$

The location that minimizes the total cost $\mathrm{F}$ is obtained by iterating through the following three steps where $(x, y)$ is the location of the facility to begin each iteration

1. For each supply source or market $\mathrm{n}$, evaluate $\mathrm{d}_{e n}$ as defined in Equation 1.

2. The total cost $\mathrm{F}$ get minimum value when

$$
\frac{\partial_{F}}{\partial_{X}}=\sum_{i=1}^{n} \frac{C_{i}\left(x-x_{i}\right)}{d_{i}}=0 \quad \frac{\partial_{F}}{\partial_{y}}=\sum_{i=1}^{n} \frac{C_{i}\left(x-x_{y}\right)}{d_{i}}=0
$$

So, the manager can obtain a new location (x', y') for the facility, where

$$
x^{\prime}=\frac{\sum_{i=1}^{n} \frac{c_{i} v_{i} x_{i}}{d_{i}}}{\sum_{i=1}^{n} \frac{c_{i} v_{i}}{d_{i}}} ; \quad y^{\prime}=\frac{\sum_{i=1}^{n} \frac{c_{i} v_{i} y_{i}}{d_{i}}}{\sum_{i=1}^{n} \frac{c_{i} v_{i}}{d_{i}}}
$$

3. If the new location ( $\left.x^{\prime}, y^{\prime}\right)$ is almost the same as $(\mathrm{x}, \mathrm{y})$ stop. Otherwise, set $(\mathrm{x}, \mathrm{y})=\left(\mathrm{x}^{\prime}, \mathrm{y}^{\prime}\right)$ and go to step1.

\section{Logistics Center Location Selection in CZT Based COG Mode}

\subsection{Procedure of calculations}

We have discussed a COG model for locating a single facility that receives raw material from supply sources and ships finished product to markets. Now, the manager illustrates the procedure for logistics center location selection in CZT. The three cities locations are shown in Figure 1.

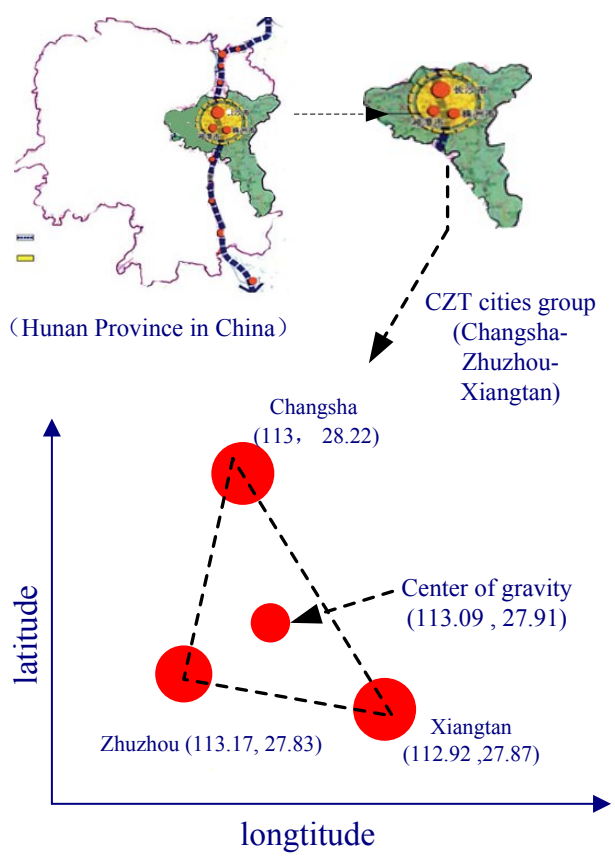

Fig.1 Coordinate locations of CZT logistics center

Tab1. Locations of Three Cities of CZT

\begin{tabular}{ccccc}
\hline \multirow{2}{*}{ Cities } & Transportaion Cost & Volume of good & \multicolumn{2}{c}{ Coordinates } \\
\cline { 4 - 5 } & Y/Ton Mile $(\mathrm{Cn})$ & MillionTons $(\mathrm{Vn})$ & Xn & Yn \\
\hline ChangSha & 0.5 & 110.62 & 113 & 28.22 \\
Zhuzhou & 0.75 & 84.49 & 113.17 & 27.83 \\
Xiangtan & 0.70 & 78 & 112.92 & 27.87 \\
\hline (Source: Bureau of Statistics of China Hunan Branch www hntj. gov.cn)
\end{tabular}

We decide to obtain the location of the new facility suing the iterative procedure described earlier. We select the COG as the initial location, so we get the first coordinates $\mathrm{X} 0=113.05$; $\mathrm{Y} 0=27.96$.

From Equation 4 , we obtains the following X1=113.06; $\mathrm{Y} 1=27.88$. Thus, we set $(\mathrm{x}, \mathrm{y})=(113.05,27.96)$ and start a new iteration, repeat steps 1 to 3.After a lot of iterations, we can obtain the coordinates $(\mathrm{x}, \mathrm{y})=(113.09,27.91)$.We thus identifies the coordinates $(x, y)=(113.09,27.91)$ as the location of the logistics center of CZT that minimizes total transportation cost.

\subsection{Result Analyses}

From the coordinate map, we can find this place is located in the white horse county in Zhuzhou city. It is near the golden triangle regional forefront and has convenient transportation network, prominent location advantages and unique geographical location, so that this place has prominent advantages. There are many highways nearby such as 320 highway, Shangrui highway, Beijing-Guangzhou, railway, qingshuitang station in the region, connecting the white horse county to the world. As north of Changsha, Xiangtan, adjacent to more than 20 large and medium-sized state-owned 
enterprises, this place has enormous regional logistic flow and information flow, so there is the idea position to build logistics centre in CZT.

\section{Conclusions}

With the rapid development in logistics in Hunan Province in center of China, the enterprise can increase efficiency, reduce energy consumption, cut costs, reduce intermediate links, and protect profit margins by means of COG approach in logistics center location selection.

This paper confirmed the location of logistics distribution center in White horse County in CZT by using COG approach. The final result about specific location is an important reference for the government and enterprises to consider with where to establish a new logistics centre or relocate an existing center.

The precise coordinates provided by the COG model may not correspond to a feasible location. The resulting solution is very often unrealistic. The location chosen by this method might be in a residential neighborhood, or may not have access to major highways, or may likely already be occupied by another business. However, by searching for a desirable site close to the recommended coordinates, the supply chain manager can locate the factory at a site that results in low transportation cost.

\section{References}

[1] Ching-Chung Kuo, Richard E.White, A Note on the Treatment of the Center-of-Gravity Method in Operations Management Textbooks. Decision Sciences Journal of Innovative Education Volume 2 Number 2 Fall 2004

[2] Vinh Van Thai, Devinder Grewal. Selecting the location of Distribution Centre in Logistics Operations: a Conceptual Framework and Case study. Asia Pacific Journal of Marketing and Logistics; 2005;17,3

[3] Bhatnagar, R., Jayaram, J. and phua, Y.C.(2003), "Relative importance of plant location factors: a cross-national comparison between Singaporc and Malaysia". Journal of business Logistics, Vol 24, No 1, pp,147-170.

[4] Burley, I.,Carrington, M.,Kobes, R and Kunstatter, G. "centre of gravity,

http://theory.uwinningpcg.ca/physics/rot/node4.html, accessed 15 Nov. 2007 